\title{
THE EFFECT OF CHITOSAN AND PROPOLIS IRRIGATION ON ROOT DENTIN MICROHARDNESS
}

\author{
Abeer Abdelhakim Elgendy*
}

\begin{abstract}
Introduction: The aim of the present study is to evaluate comparatively the action of $0.2 \%$ chitosan, $4 \%$ propolis, $2.6 \% \mathrm{NaOCl}$ and $17 \%$ EDTA on human root dentin microhardness.

Methods: Twenty recently extracted single-rooted mandibular premolar teeth were selected. The roots were split longitudinally into 2 parts (40 specimens). The specimens were randomly divided into 4 groups and were treated with $0.2 \%$ chitosan, $4 \%$ propolis, $2.6 \% \mathrm{NaOCl}$ and $17 \%$ EDTA immediately after the initial baseline microhardness measurements. A standardized volume of $2 \mathrm{ml}$ of each solution was used for 5 minutes. The reference microhardness values of untreated specimens were initially measured with a Vickers indenter under a 50-g load and a 10-second dwell time. Posttreatment microhardness values were obtained in the same manner as the initial ones. The decrease in microhardness was calculated as a percentage. Data were analyzed statistically by 1-way analysis of variance $(\mathrm{P}=.05)$ and the post hoc Tukey test for multiple comparisons at the same level of significance. Differences between pretreatment and post-treatment microhardness were statistically analyzed by using the t-test with a $P$ value of .05
\end{abstract}

Results: After treatment, all solutions significantly decreased the microhardness of root dentin $(\mathrm{P}<.05)$ however both $0.2 \%$ chitosan, $4 \%$ propolis significantly decreased dentin microhardness compared to $2.6 \% \mathrm{NaOCl}$ and $17 \%$ EDTA.

Conclusion: All the tested irrigation decreased root dentin microhardness however the effect of either $0.2 \%$ chitosan or $4 \%$ propolis decreased root dentin microhardness more than $2.6 \% \mathrm{NaOCl}$ or $17 \%$ EDTA.

KEYWORDS: Propolis, Chitosan, Irrigation, Dentin, Microhrdness.

\section{INTRODUCTION}

The main objective of root canal preparation is to remove debris loaded by bacteria from the root canal system via the use of an instrument and an irrigating solutions. Irrigation flushes away loose organic and inorganic remnants or debris resulting from the operative procedures as well as reducing the microbial content and its byproducts ${ }^{(1)}$. Root canal irrigation should have a number of physicochemical properties in order to

* Associate Professor of Endodontics, Faculty of Dentistry Ain Shams University 
be effective in endodontics ${ }^{(2)}$. Up to date, it is well known that there is no irrigant with ideal properties, and, thus, the combination of auxiliary solutions is necessary to achieve the desired effects.

Sodium hypochlorite $(\mathrm{NaOCl})$ remained the most popular root canal irrigant because of its organic tissue solvent ability and its excellent antimicrobial action so it has been recommended to remove necrotic and vital tissues from root canals. However, it is well known by its high toxicity, negative effect on the micromechanical characteristics of dentine ${ }^{(3)}$ and inability to remove the inorganic part of the smear layer ${ }^{(4,5)}$. So a decalcifying agent should be used ${ }^{(6)}$. One of the decalcifying agents is Ethylenediaminetetraacetic acid (EDTA) which was used to chemically soften the root canal dentin, dissolve the smear layer, and increase dentin permeability ${ }^{(7)}$.

Recently, natural products have been introduced aiming to decrease the cytotoxic reactions of most of the commercially used root canal irrigants. Propolis (bee glue), is a flavanoid-rich resinous product of honeybees. It has a complex chemical composition includes organic compounds such as phenolic compounds and esters, flavonoids, terpenes, beta steroids, aromatic aldehydes and alcohols, sesquiterpenes, and stilbeneterpenes ${ }^{(8)}$. Propolis has been proved to have antibacterial, antifungal, antiviral, antiinflammatory, hepatoprotective, antioxidant, antitumor, and immunomodulatory effects ${ }^{(8,9)}$. Propolis was also proved to be effective against resistant endodontic pathogens ${ }^{(10,11)}$.

Chitosan is a natural polysaccharide, (poly[1,4b-D-glucopyranosamine]), a deacetylated derivative of chitin, the second most abundant natural biopolymer ${ }^{(12)}$, which is obtained from the shells of crabs and shrimps ${ }^{(13)}$. This polysaccharide is characterized by biocompatibility, biodegradibility, bioadhesion and atoxicity to human cells ${ }^{(14)}$. It is available in a variety of physical forms: film, fiber, bead, powder, or as nanoparticles. It also presents low cost, in addition to a high chelating capacity for different metallic ions ${ }^{(13)}$. Due to these properties, chitosan was used for treatment of dentinal tubule infection, in cases of direct pulp capping ${ }^{(15)}$ and in tissue regeneration in pulp wounds ${ }^{(16)}$. Chitosan was shown to remove the smear layer when used as root canal irrigation ${ }^{(17,18)}$

During irrigation, both coronal and radicular dentin is exposed to chemical solutions that might affect the structural properties of dentin, such as microhardness, permeability, and solubility, which are capable of altering the proportion of organic and inorganic components ${ }^{(19)}$. In turn, reduction of dentin microhardness is considered indirect evidence of dentin mineral changes. There is a scarce information about the effect of both chitosan and propolis on dentin microhardness hence the aim of the present study is to evaluate comparatively the action of $0.2 \%$ chitosan, $4 \%$ propolis, $2.6 \% \mathrm{NaOCl}$ and $17 \%$ EDTA on root dentin microhardness.

\section{MATERIALS AND METHODS}

\section{Specimen selection and Preparation}

Twenty Freshly extracted, caries-free human mandibular premolar teeth were selected and stored in $0.1 \%$ thymol solution until use. The teeth were cleaned from hard and/or soft deposits using ultrasonic scaler and were inspected to exclude any tooth with cracks, caries or fracture. Crowns were sectioned at the cement-enamel junction, and discarded. Subsequently, the roots were split longitudinally into 2 halves (40 specimens), and the root halves were embedded in autopolymerizing acrylic resin (Caulk/Dentsply, Milford, DE, USA.). The dentin surfaces of each specimen was ground smooth using increasingly finer emery papers to remove any surface scratches. 


\section{Determination of Microhardness}

Dentin microhardness of all root halves were initially measured using microhardness tester with a Vickers diamond indenter (Model HVS50, Laizhou Huayin Testing Instrument Co., Ltd. China) and recorded as control values in the Vickers number before the irrigation phase. Three separate indentations parallel to the edge of the root canal lumen, $0.5 \mathrm{~mm}$ from the root canal, at a depth of $100 \mu \mathrm{m}$ from the pulp-dentin interface, each using a 50-g (HV 0.05) load and a 10-second dwell time, were made at the three different levels (coronal, middle and apical) of the root dentin in each sample. The hardness values were obtained as the average of the results for the 3 indentations (V1).

\section{Irrigant preparation}

The $0.2 \%$ chitosan solution was prepared by dissolving 0.2 gm of low molecular weight chitosan powder (Sigma-Aldrich, St. Louis, MO, USA) in $100 \mathrm{~mL}$ of deionized water ${ }^{(20)}$. The mixture was agitated using a magnetic agitator (Shanghai Instrument equipment Co., Ltd, China) for $2 \mathrm{~h}$ to obtain homogenous clear solution and stored at $4{ }^{\circ} \mathrm{C}$ in dark until further use.

$4 \%$ propolis solution was prepared by dissolving 4gm propolis powder (Imtenan Company, Cairo, Egypt) in $100 \mathrm{ml}$ of dimethyl Sulfoxide (DMSO) (Tedia company, Inc, Fairfield USA). The remaining beeswax, bee parts and wood chips were removed. Propolis solution was filtered to remove any remaining undissolved particels

\section{Specimen treatment}

Specimens were randomly divided into 4 groups $(n=10)$ and were treated with the irrigation solutions immediately after the initial baseline microhardness measurements. A basin-like pink wax was built following the tooth outline to contain and hold the irrigant. The exposed dentin surface of the each sample was treated for 5 minutes with $2 \mathrm{~mL}$ of one of the following irrigants: group 1; $0.2 \%$ chitosan, group $2 ; 4 \%$ propolis, group $3 ; 2.6 \%$ $\mathrm{NaOCl}$ (Clorox, Oakland, CA) and group 4; $17 \%$ EDTA (Sigma-Aldrich, Munich, Germany). After surface treatment, the specimens were rinsed with distilled water, and blotted dry. Indentations were made on each specimen adjacent to the initials in the same manner, and the microhardness values were recorded (V2). For each specimen, the decreases in microhardness were calculated as the percentage in microhardness values ${ }^{(21)}$ as follows:

$$
\mathrm{V} 1-\mathrm{V} 2 / \mathrm{V} 1 \times 100
$$

Where $\mathrm{V} 1=$ Preoperative $\mathrm{VHN}$ and V2 = Postoperative VHN

\section{Statistical Analysis}

Differences between pretreatment and posttreatment microhardness were statistically analyzed by using the $\mathrm{t}$-test with a P value of .05. Comparisons between experimental groups were performed by using one-way analysis of variance, followed by Tukey honestly significant difference test at $\mathrm{p}=$ 0.05 .

\section{RESULTS}

Comparing Vickers microhardness values (mean \pm standard deviation) for root dentine of all groups before treatment, there was statistically insignificant difference (table 1). After treatment, all solutions significantly decreased the microhardness of root dentin $(\mathrm{P}<.05)$ (table 1$)$. Mean percentage of change in Vickers microhardness values (mean \pm standard deviation) of root canal dentine after treatment using the test solutions is summarized in Table 2. 
TABLE (1) Minimum, Maximum, Median and Mean Vickers Microhardness Values of Root Dentin Specimens before and after Treatment

\begin{tabular}{|c|c|c|c|c|c|c|}
\hline & & $\begin{array}{c}\text { Group } 1 \\
0.2 \% \text { chitosan }\end{array}$ & $\begin{array}{c}\text { Group } 2 \\
4 \% \text { propolis }\end{array}$ & $\begin{array}{c}\text { Group } 3 \\
2.6 \% \mathrm{NaOCl}\end{array}$ & $\begin{array}{c}\text { Group } 4 \\
17 \% \text { EDTA }\end{array}$ & p-value \\
\hline \multirow{2}{*}{ Minimum } & Pre & 64.1 & 62.3 & 62.3 & 61.6 & \multirow{10}{*}{0.748} \\
\hline & Post & 46.9 & 42.9 & 58.4 & 51.6 & \\
\hline \multirow{2}{*}{ Maximum } & Pre & 75.8 & 77.5 & 71.3 & 71.3 & \\
\hline & post & 61.2 & 61.0 & 64.23 & 68.3 & \\
\hline \multirow{2}{*}{ Median } & Pre & 73.7 & 70.3 & 68.7 & 69.7 & \\
\hline & post & 53.4 & 53.1 & 60.5 & 60.7 & \\
\hline \multirow{2}{*}{ Mean \pm SD } & Pre & $71.5 \pm 9.97$ & $70.51 \pm 4.84$ & $67.61 \pm 3.47$ & $67.33 \pm 4.31$ & \\
\hline & Post & $54.03 \pm 4.9$ & $53.98 \pm 4.8$ & $60.99 \pm 3.4$ & $59.66 \pm 4.3$ & \\
\hline \multicolumn{2}{|c|}{ Difference } & 17.47 & 16.55 & 6.61 & 7.67 & \\
\hline \multicolumn{2}{|c|}{ p-value } & 0.0001 & 0.0001 & 0.003 & 0.0009 & \\
\hline
\end{tabular}

TABLE (2) Mean percentage of change in Vickers Microhardness Values (mean \pm standard deviation) of root dentine after treatment with the test solutions

\begin{tabular}{|c|c|c|c|c|c|}
\hline & $\begin{array}{c}\text { Group 1 } \\
0.2 \% \text { chitosan }\end{array}$ & $\begin{array}{c}\text { Group 2 } \\
4 \% \text { propolis }\end{array}$ & $\begin{array}{c}\text { Group 3 } \\
2.6 \% \mathrm{NaOCl}\end{array}$ & $\begin{array}{c}\text { Group 4 } \\
17 \% \text { EDTA }\end{array}$ & p-value \\
\hline Mean \pm SD & $27.16 \pm 5.13^{\mathrm{a}}$ & $26.32 \pm 5.06^{\mathrm{a}}$ & $8.31 \pm 3.48^{\mathrm{b}}$ & $14.25 \pm 1.45^{\mathrm{b}}$ & $<0.0001$ \\
\hline
\end{tabular}

Means with different superscript letters are statistically significant at $p<0.05$.

\section{DISCUSSION}

During root canal cleaning and shaping, the use of root canal irrigation either for cleanliness or the smear layer removal can lead to structural changes on the dentin surface, which may modify its physical properties ${ }^{(22-24)}$. It was reported that there is a positive correlation between hardness and the mineral content of the tooth ${ }^{(25)}$. Using new irrigation must be preceded by laboratory studies that investigate the benefits and consequences to the human beings ${ }^{[26]}$. Hence, the effect of $0.2 \%$ chitosan solution and $4 \%$ propolis solution on root dentin microhardess was the aim of the present study.

The Vickers test was used in the present study as it is less sensitive to surface conditions among the microhardness measurement methods and more sensitive to measurement errors when equal loads are applied ${ }^{(27)}$. Microhardness of dentin decreases as the indentations are made closer to the pulp ${ }^{(28)}$. In the present study, to measure the Vickers hardness values for dentin, indentations were made $0.5 \mathrm{~mm}$ from the root canal walls at three different levels (coronal, middle and apical) of the root canal and were done at a depth of $100 \mu \mathrm{m}$ for standardization, each using a 50-g load and a 10 -second dwell time. Lighter load and less of a dwell time were used because of the inverse correlation between dentin microhardness and tubular density ${ }^{(21)}$.

The results of the present study revealed that all the tested irrigation significantly decreased the microhardness of root canal dentin however the effect of either $0.2 \%$ chitosan or $4 \%$ propolis was more pronounced. Chitosan is a polymer, derived from chitosin, is a polysaccharide characterized by 
biocompatibility ${ }^{(14)}$ and chelating capacity ${ }^{(13)}$. It is hydrophilic in nature, when came in an intimate contact with root canal dentin, could be adsorbed to root canal wall. It is cationic in nature, has large number of free hydroxyl and amino groups ${ }^{(29)}$.

Regarding to the effect of chitosan on root dentin, its free hydroxyl and amino groups could be responsible for the ionic interaction with the dentin calcium ions. The exact mechanism of action is not fully understood, but it might be believed that adsorption, ionic exchange and chelation are responsible for the formation of complexes between the substance and the metallic ions. The type of interaction that occurs depends on the ion involved, the chemical structure of chitosan, and the $\mathrm{pH}$ of the solution ${ }^{(30)}$. There are two explanation about the chelation process of chitosan. The first, known as the model of the bridge, is grounded in the theory that two or more amino groups of one chitosan chain will bind to the same metallic ion ${ }^{(31)}$. The other supports the theory that only one amino group of the structure of the substance is involved in the binding, that being the metallic ion "anchored" to the amino group ${ }^{(32)}$. A previous study by Pimenta et al. ${ }^{(33)}$ evaluated the effect of chitosan on root dentin microhardness and found that, there were no significant differences among $0.2 \%$ chitosan, $15 \%$ EDTA however the results of the present study revealed significant difference between $0.2 \%$ chitosan and 17\% EDTA this could be attributed to difference in methodology and testing.

Previous researches evaluated propolis chemistry proved that its chemical composition was highly variable and depended on the local flora at the site of collection ${ }^{(34-36)}$. The composition of Egyptian propolis contain the characteristic groups of poplar propolis ${ }^{(37)}$. These groups are aliphatic acids, aromatic acids, aromatic acid esters, flavonoids and some triterpenoids. The presence of flavonoids and esters of phenolic acids might be the causative factor in the significant reduction in dentin microhardness caused by $4 \%$ propolis. Phenolics has the ability of chelating metals ${ }^{(38)}$. These weak acids could be adsorbed on hydroxyapatite molecules ${ }^{(39)}$. After adsorption, the reaction mechanism is equilibrium reactions with the Hydroxyappatite mineral content ${ }^{(40)}$.

The results of this study demonstrated that EDTA and $\mathrm{NaOCl}$ significantly decreased the microhardness of the root dentin. These results came in accordance with different previous studies ${ }^{(24,27,41)}$. The effect of $\mathrm{NaOCl}$ could be attributed to its dissolving effect for both collagen components of dentin and magnesium and phosphate ions while it increase the amount of dentinal carbonate ${ }^{(24,42)}$. Furthermore, it was proved that $\mathrm{NaOCl}$ treatment significantly altered the $\mathrm{Ca} / \mathrm{P}$ ratio of the root dentin surface ${ }^{(43)}$. As the degree of dentin mineralization may affect the dentin hardness ${ }^{(44)}$, the effect of $\mathrm{NaOCl}$ on the mineral content could be responsible for changes in dentin microhardness. Also 17\% EDTA solution causes significant decrease in root dentin microhardness. Using chelating agents cause dentin softening by removing calcified components of dentin which in turn causes reduction in dentin microhardness ${ }^{(1,24,27)}$. Within the limitation of the present study, it can be concluded that: All the tested irrigation decreased root dentin microhardness however the effect of either $0.2 \%$ chitosan or $4 \%$ propolis decreased root dentin microhardness more than $2.6 \% \mathrm{NaOCl}$ or $17 \%$ EDTA.

Finally, it is recommended that prior to the clinical use of a new substance or product, further studies are needed to investigate in detail its physical, chemical and biological properties in order to verify the benefits and consequences to humans.

\section{ACKNOWLEDGMENTS}

The authors deny any conflicts of interest related to this study. 


\section{REFERENCES}

1. HÜlsmann $\mathbf{M}$, Heckendorff $\mathrm{M}$, Lennon A. Chelating agents in root canal treatment: mode of action and indications for their use. Int Endod 2003;36:810-30.

2. Cathro P. The importance of irrigation in endodontics. Contemp Endod 2004;1:3-7.

3. Ari H, Erdemir A, Belli S. Evaluation of the effect of endodontic irrigation solutions on the microhardness and the roughness of root canal dentin. J Endod 2004;30:792-5.

4. McComb D, Smith DC. A preliminary scanning electron microscopic study of root canals after endodontic procedures. J Endod 1975;1:238-42.

5. Gernhardt CR, Eppendorf K, Kozlowski A, Brandt M. Toxicity of concentrated sodium hypochlorite used as an endodontic irrigant. Int Endod J 2004;37:272-80.

6. De-Deus G, Souza EM, Marins JR, Reis C, Paciornik S, Zehnder M. Smear layer dissolution by peracetic acid of low concentration. Inter Endod J 2011;44:485-90.

7. Guerisoli DM, Marchesan MA, Walmsley AD, Lumley PJ, Pecora JD. Evaluation of smear layer removal by EDTAC and sodium hypochlorite with ultrasonic agitation. Int En$\operatorname{dod} \mathrm{J} 2002 ; 35: 418-21$.

8. Bankova V. Chemical diversity of propolis and the problem of standardization. J Ethnopharmacol 2005;100:114-7.

9. Viuda-Martos M, Ruiz-Navajas Y, Fern andez-L opez J, P erez-Alvarez JA. Functional properties of honey, propolis, and royal jelly. J Food Sci 2008;73: R117-24.

10. Madhubala M, Srinivasan N, Ahamed S. Comparative evaluation of propolis and triantibiotic mixture as an intracanal medicament against Enterococcus faecalis. J Endod 2011;37:1287-9.

11. Kayaoglu G, Ömürlü $€ \mathrm{H}$, Akca G, et al. Antibacterial Activity of Propolis versus Conventional Endodontic Disinfectants against Enterococcus faecalis in Infected Dentinal Tubules. J Endod 2011;37:376-381.

12. Shrestha A, and Kishen A. Antibacterial Nanoparticles in Endodontics: A Review J Endod 2016;42:1417-1426,

13. Kurita K. Chemistry and application of chitin and chitosan. Polym Degrad Stab 1998;59:117-120.

14. Akncbay H, Senel S, Ay ZY. Application of chitosan gel in the treatment of chronic periodontitis. J Biomed Mater Res B Appl Biomater 2007;80:290-296.
15. Shrestha A, Kishen A. The effect of tissue inhibitors on the antibacterial activity of chitosan nanoparticles and photodynamic therapy. J Endod 2012;38:1275-8.

16. Yao Q, Liu W, Gou Z, Yan J, Song Q, Chen C, et al. Preparation, characterization, and cytotoxicity of various chitosan nanoparticles. J Nanomater 2013;13:1-6

17. Silva P, Guedes D, Nakadi F, Pe 'cora J \& Cruz-Filho A. Chitosan: a new solution for removal of smear layer after root canal instrumentation. Int Endod J 2013; 46:332-338,

18. Darrag A. Effectiveness of different final irrigation solutions on smear layer removal in intraradicular dentin Tanta Dent J 2014; 11: 93-99.

19. Rotstein I, Dankner E, Goldman A, et al. Histochemical analysis of dental hard tissues following bleaching. J Endod 1996;22:23-5.

20. Upadya M, Shrestha A and Kishen A. Role of Efflux Pump Inhibitors on the Antibiofilm Efficacy of Calcium Hydroxide, Chitosan Nanoparticles, and Light-activated Disinfection. J Endod 2011;37:1422-1426.

21. Akcay I and Sen B. The Effect of Surfactant Addition to EDTA on Microhardness of Root Dentin. J Endod 2012;38:704-707

22. Cameron JA. The effect of a fluorocarbon surfactant on the surface tension of the endodontic irrigant, sodium hypochlorite. A preliminary report. Aust Dent J 1986;31:364-8

23. Sim TP, Knowles JC, Ng YL, Shelton J, Gulabivala K. Effect of sodium hypochlorite on mechanical properties of dentine and tooth surface strain. Int Endod J 2001; $34: 120-32$

24. Sayin TC, Serper A, Cehreli ZC, Otlu HG. The effect of EDTA, EGTA, EDTAC, and tetracycline- $\mathrm{HCl}$ with and without subsequent $\mathrm{NaOCl}$ treatment on the microhardness of root canal dentin. Oral Surg Oral Med Oral Pathol Oral Radiol Endod 2007;104:418-24.

25. Panighi $M$ and G'Sell C. Influence of calcium concentration on the dentin wettability by an adhesive. J Biomed Mater Res 1992;26:1081-9.

26. Sirtes G, Waltimo T, Schaetzle M, Zehnder M. The effects of temperature on sodium hypochlorite short-term stability, pulp dissolution capacity, and antimicrobial efficacy. J Endod 2005;31:669-71

27. Cruz-Filho AM, Sousa-Neto MD, Savioli RN, Silva RG, Vansan LP, P ecora JD. Effect of chelating solutions on the 
microhardness of root canal lumen dentin. J Endod 2011; $37: 358-62$

28. Pashley D, Okabe A, Parham P. The relationship between dentin microhardness and tubule density. Endod Dent Traumatol 1985;1:176-9.

29. Zhang J, Xia Z, Liu P, Cheng Q, Tahirou T, Gu W, et al. Chitosan modification and pharmaceutical/biomedical applications. Mar Drugs 2010;8:1962-87.

30. Rhazi M, Desbrières J, Tolaimate A, Rinaudo M, Vottero $P$, Alagui A, et al.. Influence of the nature of the metal ions on the complexation with chitosan. Application to the treatment of liquid wast. Eur Polym J 2002;38:1523-1530

31. Blair HS, Ho TC. Studies in the adsorption and diffusion of ions in chitosan. J Chem Technol Biotechnol 1981;31:610 .

32. Domard A.pH and c.d. measurements on a fully deacetylated chitosan: application to CuII-polymer interactions. Int J Biol Macromol 1987; ;9:98-104.

33. Pimenta JA, Zaparolli D, P ecora JD, Cruz-Filho AM. Chitosan: effect of a new chelating agent on the microhardness of root dentin. Braz Dent J 2012;23:212-7

34. Marcucci, M.C. Propolis: chemical composition, biological properties and therapeutic activity. Apidologie 1995; 26: 83-99

35. Bankova, V., de Castro, S.L., Marcucci, M.C. Propolis: recent advances in chemistry and plant origin. Apidologie 2000; 31: 3-15
36. Huang $\mathrm{S}$, Zhang $\mathrm{C}$, Wang $\mathrm{K}$ et al. Recent Advances in the Chemical Composition of Propolis. Molecules 2014; 19:19610-32

37. El Hady, F.K.A.; Hegazi, A.G. Egyptian propolis: 2. Chemical composition, antiviral and antimicrobial activities of East Nile Delta propolis. Extraction 2000; 57: 386-394.

38. Croft, K.D. The chemistry and biological effects of flavonoids and phenolic acids. Ann. N. Y. Acad. Sci. 1998; 854: $435-442$

39. Vega E, Colinas P. Adsorption of fumaric and maleic acids onto hydroxyapatiet: a thermodynamic study. J Argent Chem Soc 2009;97:195-206.

40. Jonsson C. Modeling of glyphosate and metal-glyphosate speciation in solution and at solution-mineral interfaces [PhD Thesis]. Umeå, Sweden: Umeå University; 2007

41. Aslantas E, Buzoglu H, Altundasar E et al. Effect of EDTA, Sodium Hypochlorite, and Chlorhexidine Gluconate with or without Surface Modifiers on Dentin Microhardness. J Endod 2014;40:876-879.

42. Tsuda H, Ruben J, Arends J. Raman spectra of human dentin mineral. Eur J Oral Sci 1996;104:123-31.

43. Do gan H, Qalt S. Effects of chelating agents and sodium hypochlorite on mineral content of root dentin. J Endod 2001; 27:578-80

44. Arends J, ten Bosch JJ. Demineralization and remineralization evaluation techniques. J Dent Res 1992;71:924-8. 